\title{
Coinfecções por Leishmania infantum, Neospora caninum e Toxoplasma gondii em cães necropsiados da região central do Rio Grande do Sul, Brasil
}

\author{
[Coinfections by Leishmania infantum, Neospora caninum and Toxoplasma gondii in necropsied \\ dogs from the central region of Rio Grande do Sul, Brazil] \\ F.R. Ratzlaff ${ }^{1}$, A.M. Engelmann ${ }^{1}$, F.S. Luz $^{1}$, P. Bräunig ${ }^{1}$ C.M. Andrade ${ }^{2}$, R.A. Fighera ${ }^{2}$, \\ S.A. Botton ${ }^{2}$, F.S. F. Vogel ${ }^{2}$, L. Pötter ${ }^{2}$, L.A. Sangioni ${ }^{2 *}$ \\ ${ }^{1}$ Aluno de pós-graduação - Centro de Ciências Rurais - Universidade Federal de \\ Santa Maria - UFSM - Santa Maria - RS \\ ${ }^{2}$ Centro de Ciências Rurais - Universidade Federal de Santa Maria - UFSM - Santa Maria - RS
}

\section{RESUMO}

O objetivo do presente trabalho foi determinar a presença de anticorpos para Leishmania infantum, Neospora caninum e Toxoplasma gondii, por meio da reação de imunofluorescência indireta (RIFI), em cães $(\mathrm{n}=78)$ provenientes da região central do Rio Grande do Sul, necropsiados no Hospital Veterinário da Universidade Federal de Santa Maria (UFSM), bem como avaliar os dados epidemiológicos, sazonais e anátomohistopatológicos. Do total de animais avaliados, 67,9\% (53/78) apresentaram soropositividade para ao menos um agente. A ocorrência de anticorpos para L. infantum, $N$. caninum e T. gondii foi de 33,3 (26/78), 37,1 (29/78) e 43,5\% (34/78), respectivamente. Detectaram-se monoinfecções em 9,4\% (5/53) para L. infantum, $18,8 \%(10 / 53)$ para N. caninum e 20,7\% (11/53) para T. gondii. As coinfecções foram observadas em $27 / 53$ $(50,9 \%)$ dos animais. As infecções ocorreram independentemente de idade, sexo, procedência ou raça $(\mathrm{P}>0,05)$. Não se verificaram lesões anatomo-histopatológicas relacionadas aos agentes pesquisados, caracterizando-os como animais assintomáticos. Os resultados confirmaram a exposição de cães a esses protozoários na região central do RS e, em especial, demonstraram a circulação do agente causador da leishmaniose em uma área considerada indene para a enfermidade.

Palavras-chave: protozooses, anticorpos, sorologia, achados patológicos, imunofluorescência indireta

\begin{abstract}
The present paper is aimed to determine the presence of antibodies for Leishmania infantum, Neospora caninum and Toxoplasma gondii by indirect immunofluorescence (IIF) in dogs $(n=78)$ from the central region in the state of Rio Grande do Sul necropsied in the Veterinary Hospital from Universidade Federal de Santa Maria (UFSM). The data was evaluated regarding epidemiological, anatomic, and histopathologic findings. Of the total animals evaluated, 67.9\% (53/78) showed seropositivity for at least one agent. The occurrence of antibodies to L. infantum, N. caninum and T. gondii was 33.3\% (26/78) 37.1\% (29/78) and 43.5\% (34/78), respectively. The mono infections were detected in $9.4 \%$ (5/53) of $\mathrm{L}$. infantum, $18.8 \%$ (10/53) for $\mathrm{N}$. caninum and $20.7 \%$ (11/53) T. gondii. The coinfections occurred in 50.9\% (27/53) of animals. There were not anatomical and histopathological lesions regarding these surveyed agents, characterizing them as subclinical animals. The results confirmed the exposition of dogs to these protozoa in the central region of the RS, highlighting the circulation of the causer agent of leishmaniasis in an area considered harmless for the disease.
\end{abstract}

Keywords: protozoa, antibodies, serology, pathologic findings, indirect immunofluorescence

\section{INTRODUÇÃO}

O cão doméstico (Canis lupus familiaris) pode ser infectado por uma grande variedade de protozoários. Algumas espécies desses parasitos

Recebido em 5 de agosto de 2016

Aceito em 3 de fevereiro de 2017

* Autor para correspondência (corresponding author)

E-mail: lasangioni@gmail.com podem apresentar potencial zoonótico e letal para animais e humanos. $\mathrm{O}$ estudo desses agentes apresenta grande relevância epidemiológica devido à crescente relação entre o homem e os animais de estimação, implicando maiores cuidados sanitários, a fim de evitar a transmissão 
zoonótica (Coelho et al., 2013). Leishmania infantum, responsável pela leishmaniose visceral (LV) em humanos e animais, tem o cão como principal reservatório em áreas urbanas e o mosquito Lutzomya longipalpis como vetor (Hirschmann et al., 2015). No Brasil, a leishmaniose é considerada uma zoonose emergente, com ampla distribuição geográfica (Gontijo e Melo, 2004). O Rio Grande do Sul era considerado uma área indene dessa enfermidade até o ano de 2008, quando houve os primeiros casos autóctones em cães provenientes do município de São Borja. No ano de 2009, foi verificada a ocorrência de casos em seres humanos (Rio Grande do Sul, 2011).

Neospora caninum e Toxoplasma gondii são protozoários intracelulares que apresentam ampla distribuição geográfica e podem causar doença neurológica, gastrintestinal, respiratória e muscular em cães (Gennari et al., 2002). $N$. caninum é um importante agente patogênico para os bovinos e os cães (Dubey, 2003). Os canídeos são considerados os hospedeiros definitivos do agente e eliminam oocistos nas fezes (Dubey e Lindsay, 1996). Em bovinos, a neosporose pode causar abortos, o que acarreta grandes perdas econômicas na produção animal (Boaventura et al., 2008). A soroprevalência de $N$. caninum em cães é influenciada por vários fatores, entre os quais: o habitat, a idade, a raça, o convívio dos cães com bovinos e a técnica sorológica empregada no diagnóstico (Cañón-Franco et al., 2003).

T. gondii é um protozoário que acomete praticamente todas as espécies animais (Dubey e Beattie, 1988) e tem os felídeos (domésticos e selvagens) como hospedeiros definitivos. Os cães, assim como os seres humanos, são hospedeiros intermediários desse parasito (Leal e Coelho, 2014; Rey, 2013). Geralmente, a toxoplasmose ocorre de forma assintomática, em decorrência da competência imunológica do hospedeiro (Germano et al., 1985). Apesar de não atuarem como hospedeiros definitivos, os cães têm envolvimento na transmissão e manutenção desse agente. Os cães domésticos assumem uma importante função na epidemiologia dessa protozoose, como animais sentinelas da contaminação humana e ambiental, por estarem inseridos na família como mascotes e animais de companhia (Ullmann et al., 2008; Leal e Coelho, 2014). Além disso, pelo hábito da xenosmofilia, os cães podem carrear oocistos esporulados nos pelos e, dessa forma, servir de fonte de infecção para humanos (Leal e Coelho, 2014). Portanto, a soropositividade para $T$. gondii na população canina é um indicativo do risco de exposição para humanos e outros animais suscetíveis (Germano et al., 1985; Paiva et al., 2014). Coinfecções parasitárias podem ocasionar agravos clínicos em animais, principalmente em áreas endêmicas para leishmaniose (Sousa e Almeida, 2008).

Considerando-se a importância desses patógenos para os cães, o presente estudo teve como objetivo determinar a ocorrência de anticorpos contra L. infantum, $N$. caninum e $T$. gondii e verificar a coinfecção desses agentes, relacionando-os com fatores epidemiológicos. Adicionalmente, buscou-se verificar a presença da infecção por $L$. infantum, em uma área considerada indene no RS, e correlacionar sua possível presença com os achados anátomohistopatológicos obtidos na rotina do Laboratório de Patologia Veterinária da Universidade Federal de Santa Maria (UFSM).

\section{MATERIAL E MÉTODOS}

Os cães selecionados para este estudo foram oriundos da rotina de exames anátomohistopatológicos do Laboratório de Patologia Veterinária (LPV) da UFSM, no período de novembro de 2014 a abril de 2016, onde foram necropsiados 201 animais. Desse total, em 159 foi realizada prévia coleta de sangue para a realização de exames complementares durante a consulta clínica, sendo que 78 amostras permaneceram disponíveis e armazenadas a $20^{\circ} \mathrm{C}$ no banco de soro do Laboratório de Análises Clínicas Veterinárias (Lacvet) da UFSM. Os cães eram procedentes de Agudo, Jaguari, Júlio de Castilhos, Mata, Santa Maria, Santiago, São Martinho da Serra, São Vicente do Sul e Tupanciretã, municípios da região central do RS, considerados indenes para leishmaniose. Os animais foram atendidos no Hospital Universitário Veterinário (HUV), pelo setor de Clínica de Pequenos Animais da UFSM, e encaminhados para necropsia, em decorrência de morte natural ou eutanásia.

A reação de imunofluorescência indireta (RIFI) foi a técnica empregada para identificação dos animais sororreagentes para $L$. infantum, $N$. 
caninum e T. gondii. Para a detecção de anticorpos anti- $L$. infantum, utilizou-se o kit de diagnóstico comercial (Imunoteste leishmania $(\mathrm{RIFI}){ }^{\circledR}$, produzido por Imunodot Diagnósticos Ltda. ${ }^{\circledR}$-Jaboticabal/SP - Brasil), que continha o substrato antigênico desse agente. $\mathrm{O}$ ponto de corte de positividade foi considerado a diluição dos soros de 1:40 conforme orientações do fabricante. Para a detecção de anticorpos anti- $N$. caninum e anti- $T$. gondii, foram utilizados como antígenos os taquizoítos de $N$. caninum (NC-1) e T. gondii (cepa RH), adotando-se como ponto de corte de positividade as diluições de 1:50 e 1:16, respectivamente (Varandas et al., 2001). Na execução do teste, utilizou-se o conjugado, anticorpo anti-IgG de cão, produzido em coelhos, marcado com isotiocianato de fluoresceína (FITC - Sigma F-7884, São Paulo - Brasil), na diluição de 1:100. Os controles positivos e negativos foram utilizados em todas as lâminas, e foram consideradas reações positivas quando houve a fluorescência total da superfície dos protozoários pesquisados. A leitura dos testes foi executada em microscópio de epifluorescência, com aumento de 400x. Para a titulação das amostras positivas, foram realizadas diluições em dobro dos respectivos soros, sendo considerada como título final a maior diluição que mostrou fluorescência completa das promastigotas para leishmaniose e de taquizoítos para neosporose e toxoplasmose (Greca et al., 2010).

Para a análise da correlação da presença de anticorpos anti-L. infantum, anti-N. caninum e anti-T. gondii, bem como para os achados anátomo-histopatológicos, foram utilizadas as informações dos laudos disponibilizados pelo LPV, independentemente da causa mortis dos cães. As informações epidemiológicas, como raça, sexo, idade, procedência e data de realização dos procedimentos clínicolaboratoriais, foram coletadas dos prontuários de atendimento. Foi aplicado o teste do quiquadrado aos resultados obtidos, com um nível de significância de $5 \%(\mathrm{P}<0,05)$, para se verificar a associação entre a positividade das diferentes protozooses e as respectivas coinfecções, as variáveis epidemiológicas e a sazonalidade dos diagnósticos.

O referido trabalho foi aprovado pelo Comitê de Ética no Uso de Animais da Universidade
Federal de Santa Maria (CEUA/UFSM), sob o número de protocolo 1332120515.

\section{RESULTADOS E DISCUSSÃO}

Das 78 amostras de soro canino analisadas por meio da RIFI, $53 \quad(67,9 \%)$ apresentaram positividade para um ou mais protozoários, sendo: $26(33,3 \%)$ anti-L. infantum, $29(37,1 \%)$ anti- $N$. caninum e $34(43,5 \%)$ anti-T. gondii. As monoinfecções foram detectadas em 5/53 $(9,4 \%), 10 / 53(18,8 \%)$ e $11 / 53(20,7 \%)$ dos cães para L. infantum, $N$. caninum e $T$. gondii, respectivamente. As coinfecções foram observadas em 27/53 (50,9\%) dos animais, distribuídas conforme Fig. 1. As titulações máximas dos soros variaram de 1:40 a 1:5120 para L. infantum, $1: 100$ a $1: 25.000$ para $N$. caninum e 1:16 a 1:512 para T. gondii, como demonstrado na Tab. 1.

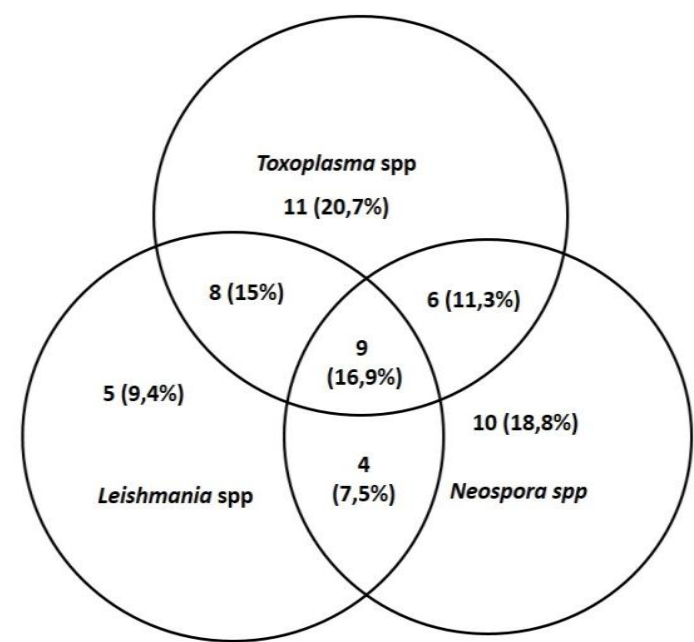

Figura 1. Distribuição dos cães soropositivos em mono ou coinfecções, de acordo com o agente pesquisado Leishmania infantum, Neospora caninum e Toxoplasma gondii, no período de novembro de 2014 a abril de 2016.

A distribuição da soroprevalência para os protozoários, conforme os dados epidemiológicos analisados (idade, sexo, procedência, raça e data de realização dos procedimentos clínico-laboratoriais, correspondendo à estação do ano), está representada na Tab. 2 . 
Tabela 1. Títulos máximos de anticorpos para Leishmania infantum, Neospora caninum e Toxoplasma gondii pela reação de imunofluorescência indireta (RIFI), em soro de cães necropsiados no Laboratório de Patologia da UFSM, no período de novembro de 2014 a abril de 2016

\begin{tabular}{|c|c|c|c|c|c|c|c|c|c|}
\hline \multicolumn{10}{|c|}{ Leishmania infantum } \\
\hline $\mathrm{T} \mathrm{M}$ & $\mathrm{n}$ & $1: 40$ & $1: 80$ & $1: 160$ & $1: 320$ & $1: 640$ & $1: 1280$ & $1: 2560$ & $1: 5120$ \\
\hline $\begin{array}{c}\text { Positivos } \\
(\%)\end{array}$ & 26 & $\begin{array}{c}3 \\
(11,5)\end{array}$ & $\begin{array}{c}11 \\
(42,3)\end{array}$ & $\begin{array}{c}7 \\
(26,9)\end{array}$ & $\begin{array}{c}1 \\
(03,8)\end{array}$ & $\begin{array}{c}2 \\
(07,6)\end{array}$ & $\begin{array}{c}1 \\
(03,8)\end{array}$ & $\begin{array}{c}0 \\
(00,0)\end{array}$ & $\begin{array}{c}1 \\
(03,8)\end{array}$ \\
\hline \multicolumn{10}{|c|}{ Neospora caninum } \\
\hline $\mathrm{T} \mathrm{M}$ & & $1: 50$ & $1: 100$ & $1: 200$ & $1: 400$ & $1: 800$ & $1: 1600$ & $1: 3200$ & $1: 25000$ \\
\hline $\begin{array}{c}\text { Positivos } \\
(\%)\end{array}$ & 29 & $\begin{array}{c}0 \\
(00,0)\end{array}$ & $\begin{array}{c}8 \\
(27,5)\end{array}$ & $\begin{array}{c}6 \\
(20,6)\end{array}$ & $\begin{array}{c}5 \\
(17,2)\end{array}$ & $\begin{array}{c}4 \\
(13,7)\end{array}$ & $\begin{array}{c}2 \\
(06,8)\end{array}$ & $\begin{array}{c}3 \\
(10,3)\end{array}$ & $\begin{array}{c}1 \\
(03,4)\end{array}$ \\
\hline \multicolumn{10}{|c|}{ Toxoplasma gondii } \\
\hline $\mathrm{T} \mathrm{M}$ & & $1: 16$ & $1: 32$ & $1: 64$ & $1: 128$ & $1: 256$ & $1: 512$ & $1: 1024$ & $1: 2048$ \\
\hline $\begin{array}{c}\text { Positivos } \\
(\%)\end{array}$ & 34 & $\begin{array}{c}2 \\
(05,8)\end{array}$ & $\begin{array}{c}5 \\
(14,7)\end{array}$ & $\begin{array}{c}10 \\
(29,4)\end{array}$ & $\begin{array}{c}11 \\
(32,3)\end{array}$ & $\begin{array}{c}3 \\
(08,8) \\
\end{array}$ & $\begin{array}{c}3 \\
(08,8)\end{array}$ & $\begin{array}{c}0 \\
(00,0)\end{array}$ & $\begin{array}{c}0 \\
(00,0)\end{array}$ \\
\hline
\end{tabular}

$\mathrm{n}=$ número de animais soropositivos; $\mathrm{T} \mathrm{M}$ = título máximo.

Tabela 2. Distribuição de cães positivos para Leishmania infantum, Neospora caninum e Toxoplasma gondii, necropsiados no Laboratório de Patologia Veterinária da UFSM, de acordo com idade, sexo, procedência, raça e período de realização dos procedimentos clínico-laboratoriais (estação do ano)

\begin{tabular}{|c|c|c|c|c|c|c|c|c|}
\hline \multirow[t]{2}{*}{ Variáveis } & \multirow[t]{2}{*}{$\mathrm{n}$} & \multicolumn{7}{|c|}{ Positivos (\%) } \\
\hline & & $\mathrm{L}^{1}$ & $\mathrm{~N}^{2}$ & $\mathrm{~T}^{3}$ & $\mathrm{~L}^{1}+\mathrm{N}^{2}$ & $\mathrm{~L}^{1}+\mathrm{T}^{3}$ & $\mathrm{~N}^{2}+\mathrm{T}^{3}$ & $\mathrm{~L}^{1}+\mathrm{N}^{2}+\mathrm{T}^{3}$ \\
\hline \multicolumn{9}{|l|}{ Idade (anos) } \\
\hline$<1$ & 00 & $0^{\mathrm{a}}(00,0)$ & $0^{\mathrm{a}}(00,0)$ & $0^{\mathrm{a}}(00,0)$ & $0^{\mathrm{a}}(00,0)$ & $0^{\mathrm{a}}(00,0)$ & $0^{\mathrm{a}}(00,0)$ & $0^{\mathrm{a}}(00,0)$ \\
\hline 1 a 7 & 18 & $3^{a}(16,6)$ & $5^{\mathrm{a}}(27,7)$ & $1^{\mathrm{a}}(05,5)$ & $1^{\mathrm{a}}(05,5)$ & $4^{\mathrm{a}}(22,2)$ & $1^{\mathrm{a}}(05,5)$ & $3^{a}(16,6)$ \\
\hline 8 a 17 & 35 & $2^{a}(05,7)$ & $5^{a}(14,2)$ & $10^{\mathrm{a}}(28,5)$ & $3^{a}(08,5)$ & $4^{\mathrm{a}}(11,4)$ & $5^{a}(14,2)$ & $6^{\mathrm{a}}(17,1)$ \\
\hline $\mathrm{P}^{*}$ & & 0,2124 & 0,9306 & 0,1270 & 0,6966 & 0,3032 & 0,3467 & 0,9655 \\
\hline \multicolumn{9}{|l|}{ Sexo } \\
\hline Macho & 25 & $2^{\mathrm{a}}(08,0)$ & $5^{\mathrm{a}}(20,0)$ & $4^{a}(16,0)$ & $2^{a}(08,0)$ & $6^{\mathrm{a}}(24,0)$ & $3^{a}(12,0)$ & $3^{a}(12,0)$ \\
\hline Fêmea & 28 & $3^{a}(10,7)$ & $5^{\mathrm{a}}(17,8)$ & $7^{a}(25,0)$ & $2^{a}(07,1)$ & $2^{\mathrm{a}}(07,1)$ & $3^{a}(10,7)$ & $6^{\mathrm{a}}(21,4)$ \\
\hline $\mathrm{P}^{*}$ & & 0,6883 & 0,7100 & 0,9829 & 0,9070 & 0,0901 & 0,8839 & 0,3660 \\
\hline \multicolumn{9}{|l|}{ Procedência } \\
\hline Santa Maria & 42 & $4^{\mathrm{a}}(09,5)$ & $8^{a}(19,0)$ & $9^{\mathrm{a}}(21,4)$ & $3^{\mathrm{a}}(07,1)$ & $7^{a}(16,6)$ & $5^{\mathrm{a}}(11,9)$ & $6^{\mathrm{a}}(14,2)$ \\
\hline Outras & 11 & $1^{\mathrm{a}}(09,0)$ & $2^{\mathrm{a}}(18,1)$ & $2^{a}(18,1)$ & $1^{\mathrm{a}}(09,0)$ & $1^{\mathrm{a}}(09,0)$ & $1^{\mathrm{a}}(09,0)$ & $3^{a}(27,2)$ \\
\hline $\mathrm{P}^{*}$ & & 0,6853 & 0,5084 & 0,9684 & 0,8292 & 0,5360 & 0,7951 & 0,3118 \\
\hline \multicolumn{9}{|l|}{ Raça } \\
\hline Definida & 27 & $2^{a}(07,4)$ & $7^{a}(25,9)$ & $8^{a}(29,6)$ & $3^{\mathrm{a}}(11,1)$ & $2^{\mathrm{a}}(07,4)$ & $2^{a}(07,4)$ & $3^{\mathrm{a}}(11,1)$ \\
\hline $\begin{array}{c}\text { Não } \\
\text { definida }\end{array}$ & 26 & $3^{\mathrm{a}}(11,5)$ & $3^{\mathrm{a}}(11,5)$ & $3^{a}(11,5)$ & $1^{\mathrm{a}}(03,8)$ & $6^{\mathrm{a}}(23,0)$ & $4^{a}(15,3)$ & $6^{a}(23,0)$ \\
\hline $\mathrm{P}^{*}$ & & 0,0773 & 0,9015 & 0,1878 & 0,3215 & 0,1146 & 0,3641 & 0,2406 \\
\hline \multicolumn{9}{|l|}{ Estações } \\
\hline Inverno & 07 & $2^{b}(28,5)$ & $0^{\mathrm{a}}(00,0)$ & $1^{\mathrm{a}}(14,2)$ & $0^{\mathrm{a}}(00,0)$ & $2^{a}(28,5)$ & $0^{\mathrm{a}}(00,0)$ & $2^{a}(28,5)$ \\
\hline Primavera & 17 & $1^{\mathrm{a}}(05,8)$ & $2^{a}(11,7)$ & $3^{a}(17,6)$ & $2^{\mathrm{a}}(11,7)$ & $5^{\mathrm{a}}(29,4)$ & $1^{\mathrm{a}}(05,8)$ & $3^{a}(17,6)$ \\
\hline Verão & 16 & $1^{\mathrm{a}}(06,2)$ & $6^{\mathrm{a}}(37,5)$ & $5^{\mathrm{a}}(31,2)$ & $1^{\mathrm{a}}(06,2)$ & $0(00,0)$ & $1^{\mathrm{a}}(06,2)$ & $2^{a}(12,5)$ \\
\hline Outono & 13 & $1^{\mathrm{a}}(07,6)$ & $2^{a}(15,3)$ & $2^{a}(15,3)$ & $1^{\mathrm{a}}(07,6)$ & $1^{\mathrm{a}}(07,6)$ & $4^{\mathrm{a}}(30,7)$ & $2^{a}(15,3)$ \\
\hline $\mathrm{P}^{*}$ & & 0,0230 & 0,2888 & 0,5789 & 0,7954 & 0,0726 & 0,0867 & 0,8239 \\
\hline
\end{tabular}

$\mathrm{n}=$ número total de amostras, ${ }^{1}$ Leishmania infantum, ${ }^{2}$ Neospora caninum, ${ }^{3}$ Toxoplasma gondii. $\mathrm{P}^{*}$ : qui-quadrado. Valores significativos $\mathrm{P}<0,05$. Valores seguidos pela mesma letra na coluna não diferem entre $\mathrm{si}(\mathrm{P} \geq 0,05)$.

Neste estudo, foi evidenciado que 26/78 (33,3\%) dos cães apresentaram anticorpos anti- $L$. infantum, sendo provenientes dos seguintes municípios: 20 (20/26) cães procedentes de Santa
Maria, um (1/26) do município de Mata, dois (2/26) de Santiago, um (1/26) de São Martinho da Serra, um (1/26) de São Vicente do Sul e um (1/26) de Tupanciretã. Esses municípios são 
considerados áreas indenes para leishmaniose. Dessa forma, os achados deste estudo elevam o número de municípios do RS considerados como áreas de risco para essa doença.

Marcondes et al. (2003) realizaram um levantamento sorológico para a presença de $L$. infantum em 203 cães, sendo 40 animais provenientes de Santa Maria/RS, e não constataram resultados positivos, bem como não se identificou o vetor flebotomíneo na região. $\mathrm{O}$ Laboratório Central do Rio Grande do Sul (Lacen/RS), no período de 2009 a 2010, analisou 5.430 amostras sorológicas caninas e obteve $20,8 \%(112 / 5.430)$ de sororreagentes. Esses animais eram provenientes de 34 municípios do estado. Porém, o estudo não abrangeu o município de Santa Maria, por não ser considerada área de risco (Rio Grande do Sul, 2011). Em 2015, Mazaro et al. (2015) descreveram três casos clínicos caninos autóctones em Santa Maria/RS, no ano de 2013. Os animais apresentaram manifestações clínicas, diagnóstico laboratorial e anatomopatológico compatíveis com leishmaniose visceral. Tal fato, aliado aos achados do presente estudo, sugere a emergência desse problema para os serviços de saúde pública da região. Dessa forma, constatase a disseminação do patógeno entre os cães na região central do RS. Adicionalmente, Hirschmann et al. (2015) encontraram uma soropositividade por meio da RIFI de 33,9\% (56/165) de cães assintomáticos provenientes de quatro municípios, de um total de 12 pesquisados, sem diagnósticos prévios de leishmaniose visceral canina (LVC), da região sul do RS. Esses resultados comprovam que a leishmaniose já está disseminada na população canina do RS e na grande maioria em cães assintomáticos. Com isso, cães infectados pelo protozoário no RS estão aptos para atuar como fonte de infecção para flebotomíneos (Rio Grande do Sul, 2011).

Neste trabalho, anticorpos anti- $N$. caninum foram detectados em 37,1\% (29/78) das amostras de soros caninos avaliadas. Cunha Filho et al. (2008) detectaram uma soropositividade de 5,5\% (6/109) nos cães urbanos e de 20,4\% (47/230) nos animais de áreas rurais de Pelotas/RS e constataram que cães de áreas rurais têm maior risco de contato quando comparados aos cães urbanos. Contudo, Boaventura et al. (2008), em Goiânia/GO, descreveram resultados semelhantes ao presente estudo, com 32,9\% (65/197) de cães positivos na RIFI, ao avaliarem amostras provenientes de cães urbanos, onde obtiveram $36,1 \% \quad(26 / 72)$ de animais provenientes do Centro de Zoonoses e 31,2\% (39/125) domiciliados atendidos por hospitais veterinários.

A infecção pelo protozoário $N$. caninum pode apresentar a forma assintomática ou desencadear sinais clínicos que podem ser facilmente confundidos com outras doenças, especialmente outras afecções neurológicas, o que dificulta o diagnóstico clínico e ressalta a importância da confirmação laboratorial (Dantas et al., 2013). Tanto as infecções clínicas como as subclínicas por N. caninum em cães são importantes epidemiologicamente, por ser o cão o principal hospedeiro capaz de eliminar oocistos no ambiente, o que representa fator de risco para a ocorrência de abortos em bovinos (Boaventura $e t$ al., 2008) e para a transmissão horizontal para outros hospedeiros.

A ocorrência de anticorpos anti-T. gondii foi de $43,5 \%$ (34/78), com a titulação variando de 1:16 a 1:512, resultado que indica a exposição ao agente. Giraldi et al. (2002) encontraram títulos de 1:4096 em animais que apresentavam distúrbios neurológicos, o que pode estar relacionado à infecção aguda. Germano et al. (1985) verificaram uma prevalência de $91 \%$ de T. gondii em cães oriundos de Campinas/SP. Esse alto índice pode estar associado ao baixo consumo de ração pelos cães ou ao menor uso de vacina contra cinomose. Esse vírus apresenta um caráter imunossupressor, o que aumenta as chances de infecção pelo protozoário (Giraldi et al., 2002). Os cães são considerados animais sentinelas para a ocorrência de T. gondii no meio ambiente (Ullmann et al., 2008) e podem adquirir a infecção pelo hábito alimentar ou pelo estreito contato com o solo contaminado (Langoni et al., 2006). A soroprevalência evidenciada nesta pesquisa expressa a possibilidade de risco de infecção por $T$. gondii para os humanos, e os cães podem compartilhar fontes similares de infecção no mesmo ambiente (Marques et al., 2009).

As coinfecções representaram a maioria neste estudo $(50,9 \% ; 27 / 53)$. Porém, a presença de um agente não favoreceu a infecção por outro $(\mathrm{P}>0,05)$. Greca et al. (2010) também não 
observaram associação entre $L$. infantum e $N$. caninum em Bauru/SP. Os cães tiveram as mesmas chances de se infectarem para um ou mais agentes. $\mathrm{O}$ mesmo fato foi verificado no Hospital Veterinário da Universidade Federal do Piauí por Lopes et al. (2011). Por outro lado, no sul da Itália, demonstrou-se que a presença de soropositividade para $N$. caninum foi o principal fator de risco para soropositividade para $L$. infantum e vice-versa, em uma área endêmica para leishmaniose visceral, em cães assintomáticos. Esses autores afirmaram que, na região estudada, a coinfecção é muito comum em cães e a infecção por um protozoário pode aumentar a suscetibilidade para o outro, provavelmente pelo estado imunológico dos cães avaliados. Os autores também evidenciaram que títulos significativamente maiores para $L$. infantum ocorreram em cães coinfectados (Cringoli et al., 2002). Nesse estudo, os animais que apresentaram as maiores titulações para $L$. infantum apresentaram coinfecções com $N$. caninum e $T$. gondii.

Outros autores buscaram avaliar as coinfecções de $L$. infantum, N. caninum ou T. gondii com outros agentes, como: Erlichia canis (Girardi et al., 2014; Sousa e Almeida, 2008), Babesia spp. (Guimarães et al., 2009) e o vírus da cinomose (Aguiar et al., 2012). O vírus da cinomose desencadeia imunossupressão, o que torna $o$ animal mais suscetível ao desenvolvimento de infecções secundárias por $N$. caninum ou $T$. gondii, considerados protozoários oportunistas (Aguiar et al., 2012). A ocorrência de coinfecções pode contribuir para a manifestação clínica de alguma das protozooses, em virtude do caráter oportunista dos agentes parasitários, em relação ao estabelecimento da doença (Girardi et al., 2014). No entanto, não foi constatada essa relação no presente estudo.

A presença de anticorpos contra os agentes pesquisados ocorreu em animais de diferentes idades, sem predominância de sexo ou raça, provenientes de Santa Maria e outras cidades da região central do estado do $\mathrm{RS}(\mathrm{P}>0,05)$. A maior ocorrência dos diagnósticos de L. infantum foi observada no período da realização dos procedimentos clínico-laboratoriais (estação do ano) nos meses de inverno $(\mathrm{P}=0,02)$. Uma possível justificativa para essa ocorrência sazonal poderia estar relacionada às dinâmicas das populações dos vetores. Comumente, a densidade dos flebotomíneos oscila pouco, em locais de clima quente e úmido. Porém, no RS, há características climáticas demarcadas por mudanças de temperaturas e distribuição desigual das chuvas, o que ocasiona a oscilação na densidade de insetos, que declina principalmente nos meses frios (Rey, 2013). Dessa forma, pode-se sugerir que a população de vetores foi maior nos meses de outono, época de temperaturas amenas e com alta umidade na região de Santa Maria/RS, aumentando-se as chances de infecção da população canina e o surgimento da soropositividade nos meses subsequentes, na estação do inverno. Todavia, salienta-se que esse fator foi relacionado ao período do diagnóstico clínico-laboratorial, podendo, assim, ocorrer a infecção em qualquer estação do ano.

Varandas et al. (2001) e Guimarães et al. (2009) obtiveram resultados semelhantes a este trabalho, em relação à variável sexo, em um levantamento sorológico para $N$. caninum e $T$. gondii, na região nordeste do estado de São Paulo e no município de Lavras/MG, respectivamente. Nesse estudo, machos e fêmeas da espécie canina estiveram submetidas às mesmas condições de risco. Tais resultados também estão em conformidade com Boaventura et al. (2008), que não constataram diferença significativa para as variáveis sexo e procedência com relação ao $N$. caninum, em Goiânia. Aguiar et al. (2012) também não acharam associações significativas em cães de Botucatu/SP, quando avaliaram cães com o vírus da cinomose e infecções oportunistas por $N$. caninum e $T$. gondii, pois nenhuma associação foi detectada entre a idade, o sexo, a raça e os sinais clínicos. Sousa e Almeida (2008) afirmaram não terem encontrado predisposição sexual e racial para $L$. infantum, em Cuiabá/MT. Cringoli et al. (2002), no entanto, obtiveram uma associação entre a raça Boxer e a presença de anticorpos para $N$. caninum. Dubey e Lindsay (1996) verificaram uma correlação entre cães da raça Setter e Pit Bulls com a infecção por $L$. infantum. Todavia, nesse estudo, não foi observada correlação entre animais de raça definida e indefinida e soropositividade para os protozoários pesquisados, provavelmente pelo fato de os cães serem domiciliados. Esses animais são tratados da mesma forma e possuem as mesmas chances de se infectarem, sendo de raça definida ou não. 
No presente estudo, não houve significância com relação à idade para nenhum dos agentes, o que indica que os animais são expostos aos protozoários ainda muito jovens. Em relação a $T$. gondii, Guimarães et al. (2009) verificaram que houve um número maior de sororreagentes com o incremento da idade, atribuindo-se a essa diferença ao aumento da chance de exposição ao parasita com o passar do tempo.

Não se observaram lesões anátomohistopatológicas características que pudessem ser atribuídas a algum dos três protozoários estudados, sem distinção entre os cães sorologicamente positivos e negativos $(\mathrm{P}>0,05)$. Os achados encontrados neste estudo demonstraram que, entre as principais causa mortis, foram relatadas: diabete melito descompensada, epilepsia idiopática, tumores, cirrose, intoxicação por diaceturato de diminazeno, septicemia, pancreatite aguda, insuficiência renal aguda e crônica, insuficiência cardíaca congestiva, miocardiopatia hipertrófica, trauma, cinomose, crise hemolítica crônica, leptospirose, entre outras. Interessantemente, dois cães soropositivos apresentaram reação linfoplasmocitária decorrente de infecção por Leishmania spp. e, ainda assim, permaneceram assintomáticos, o que agrava a situação na região onde os cães se mantêm como reservatórios do protozoário.

\section{CONCLUSÕES}

A detecção de anticorpos verificada neste estudo contribui para o conhecimento da epidemiologia da leishmaniose, neosporose e toxoplasmose canina na região central do RS. A realização do inquérito sorológico, associado aos achados histopatológicos, permitiu concluir que os animais estiveram expostos aos agentes e mantiveram-se assintomáticos. A infecção ocorreu sem predomínio de raça, idade e sexo. Dessa forma, confirmou a circulação desses agentes e caracterizou o cão como animal sentinela para essas infecções. Tal fato é de grande relevância, principalmente em casos de agentes zoonóticos, uma vez que os animais deste estudo não eram errantes e dividiam o mesmo ambiente com os humanos, que estão expostos aos mesmos riscos. Além disso, a constatação de que cães assintomáticos sorologicamente positivos para $L$. infantum podem vir a desempenhar o papel de multiplicador do agente, em seis municípios do $\mathrm{RS}$, considerados áreas indenes, é um dado relevante. Essa constatação poderá contribuir com os serviços de saúde pública para elaborar medidas profiláticas, com o intuito de prevenir casos autóctones e elaborar estratégias de controle e profilaxia, a fim de se diminuir o risco de infecções por essas protozooses em cães e humanos.

\section{REFERÊNCIAS}

AGUIAR, D.M.; AMUDE, A.M.; SANTOS, L.G.F. et al. Canine distemper virus and Toxoplasma gondii coinfection in dogs with neurological signs. Arq. Bras. Med. Vet. Zootec., v.64, p.221-224, 2012.

BOAVENTURA, C.M.; OLIVEIRA, V.S.F.; MELO, D.P.G. et al. Prevalência de Neospora caninum em cães de Goiânia. Rev. Patol. Trop., v.37, p.15-22, 2008.

CAÑÓN-FRANCO, W.A.; BERGAMASCHI, D.P.; LABRUNA, M.B. et al. Prevalence of antibodies to Neospora caninum in dogs from Amazon, Brazil. Vet. Parasitol., v.115, p.71-74, 2003.

COELHO, W.M.D.; COELHO, A.; TEIXEIRA, W.F.P. et al. Detecção de coinfecções por Leishmania (L.) chagasi, Trypanosoma evansi, Toxoplasma gondii e Neospora caninum em cães. Ars Vet., v.29, p.169174, 2013.

CRINGOLI, G.; RINALDI, L.; CAPUANO, F. et al. Serological survey of Neospora caninum and Leishmania infantum co-infection in dogs. Vet. Parasitol., v.106, p.307-313, 2002.

CUNHA FILHO, N.A.; LUCAS, A.S.; PAPPEN, F.G. et al. Fatores de risco e prevalência de anticorpos antiNeospora caninum em cães urbanos e rurais do Rio Grande do Sul, Brasil. Rev. Bras. Parasitol. Vet., v.17, Supl.1, p.301-306, 2008.

DANTAS, S.B.A.; FERNANDES, A.R.F.; SOUZA NETO, O.L. et al. Ocorrência e fatores de risco associados às infecções por Toxoplasma gondii e Neospora caninum em cães no município de Natal, Estado do Rio Grande do Norte, Nordeste do Brasil. Cienc. Rural, v.43, p.2042-2048, 2013.

DUBEY, J.P. Review of Neospora caninum and neosporosis in animals. Korean J. Parasitol., v.41, p.1-16, 2003.

DUBEY, J.P.; BEATTIE, C.P. Toxoplasmosis of animals and man. Boca Raton: CRC, 1988, 220p.

DUBEY, J.P.; LINDSAY, D.S. A review of Neospora caninum and neosporosis. Vet. Parasitol. v.67, p.1-59, 1996. 
GENNARI, S.M.; YAI, L.E.O.; D’ÁURIA, S.N.R. et al. Occurrence of Neospora caninum antibodies in sera from dogs of the city of São Paulo, Brazil. Vet. Parasitol., v.106, p.177-179, 2002.

GERMANO, P.M.L.; ERBOLATO, E.B.; ISHIZUKA, M.M. Estudo sorológico da toxoplasmose canina, pela prova de imunofluorescência indireta, na cidade de Campinas, 1981. Rev. Fac. Med. Vet. Zootec. Univ. São Paulo, v.22, p.53-58, 1985.

GIRALDI, J.H.; BRACARENSE， A.P.F.R.L.; VIDOTTO, O. et al. Sorologia e histopatologia de Toxoplasma gondii e Neospora caninum em cães portadores de distúrbios neurológicos. Semin. Cienc. Agrar., v.23, p.9-14, 2002.

GIRARDI, A.F.; LIMA, S.R.; MELO, A.L.T. et al. Ocorrência de anticorpos anti-Toxoplasma gondii e Ehrlichia canis em cães com alterações nervosas atendidos em hospital veterinário universitário. Semin. Cienc. Agrar., v.35, p.1913-1922, 2014.

GONTIJO, C.M.F.; MELO, M.N. Leishmaniose visceral no Brasil: quadro atual, desafios e perspectivas. Rev. Bras. Epidemiol., v.7, p.338-349, 2004.

GRECA, H.; SILVA, A.V.; LANGONI, H. Associação entre a presença de anticorpos antiLeishmania sp. e anti-Neospora caninum em cães de Bauru, SP. Arq. Bras. Med. Vet. Zootec., v.62, p.224227, 2010.

GUIMARÃES, A.M.; ROCHA, C.M.B.M.; OLIVEIRA, T.M.F.S. et al. Fatores associados à soropositividade para Babesia, Toxoplasma, Neospora e Leishmania em cães atendidos em nove clínicas veterinárias do município de Lavras, MG. Rev. Bras. Parasitol. Vet., v.18, Supl.1, p.49-53, 2009.

HIRSCHMANN, L.C.; BROD, C.S.; RADIN, J. et al. Leishmaniose visceral canina: comparação de métodos sorológicos em cães de área indene do Rio Grande do Sul no Brasil. Rev. Patol. Trop., v.44, p.33-44, 2015.

LANGONI, H.; MODOLO, J.R.; PEZERICO, S.B. et al. Serological profile of anti-Toxoplasma gondii antibodies in apparently healthy dogs of the city of Botucatu, São Paulo State, Brazil. J. Venom. Anim. Toxins Incl. Trop. Dis., v12, p.142-148, 2006.

LEAL, P.D.S.; COELHO, C.D. Toxoplasmose em cães: uma breve revisão. Coccid, v.2, p.2-39, 2014.

LOPES, M.G.; MENDONÇA, I.L.; FORTES, K.P. et al. Presence of antibodies against Toxoplasma gondii, Neospora caninum and Leishmania infantum in dogs from Piauí. Rev. Bras. Parasitol. Vet., v.20, p.111-114, 2011.
MARCONDES, C.B.; PIRMEZ, C.; SILVA, E.S. et $a l$. Levantamento de leishmaniose visceral em cães de Santa Maria e municípios próximos, Estado do Rio Grande do Sul. Rev. Soc. Bras. Med. Trop., v.36, p.499-501, 2003.

MARQUES, J.M.; ISBRECHT, F.B.; LUCAS, T.M. et al. Detecção de anticorpos anti-Toxoplasma gondii em animais de uma comunidade rural do Mato Grosso do Sul, Brasil. Semin. Cienc. Agrar., v.30, p.889-898, 2009.

MAZARO, R.D.; PEREIRA, P.R.; BIANCHI, R.M. et al. Identificação de casos autóctones de leishmaniose em cães da Região Central do RS atendidos no HVUUFSM (2010-2014). In: REUNIÃO ANUAL DA SOCIEDADE BRASILEIRA PARA O PROGRESSO DA CIÊNCIA, 67., 2015, São Carlos. Anais... São Carlos: Universidade Federal de São Carlos, 2015. 1 CD.

PAIVA, J.B.; SANTOS, E.A.; PINTO, J.F.N. et al. Avaliação da ocorrência, fatores de risco e associações laboratoriais hematológicas para Toxoplasmose em cães na região de Jataí- GO, Brasil. Encicl. Biosfera, v.10, p.502-509, 2014.

REY, L. Parasitologia: parasitos e doenças parasitárias do homem nos trópicos ocidentais. 4.ed. Rio de Janeiro: Guanabara Koogan, 2013. p.724.

RIO Grande do Sul. Ministério da Saúde. Centro Estadual de Vigilância em Saúde. Bol. Epidemiol., v.13, p.1-8, 2011. Disponível em: <http://www.saude.rs.gov.br/upload/1337355106_v.13 ,\%20n.1,\%20mar.,\%202011.pdf.>. Acessado em: 28 mai. 2016.

SOUSA, V.R.F.; ALMEIDA, A.B.P.F. Coinfecção entre leishmaniose visceral e ehrlichiose monocítica em cães de Cuiabá, Mato Grosso. Acta Sci. Vet., v.36, p.113-117, 2008.

ULLMANN, L.S.; GUIMARÃES, F.F.; FORNAZARI, F. et al. Ações de vigilância continuada, papel do cão como animal sentinela para toxoplasmose. Rev. Bras. Parasitol. Vet., v.17, Supl.1, p.345-347, 2008.

VARANDAS, N.P.; RACHED, P.A.; COSTA, G.H.N. et al. Frequência de anticorpos anti-Neospora caninum e anti-Toxoplasma gondii em cães da região nordeste do Estado de São Paulo. Correlação com neuropatias. Semin. Cienc. Agrar., v.22, p.105-111, 2001. 